\title{
BIODEGRADASI ANAEROBIK BIOMASSA TANAMAN LAUT DAN PRODUKSI BIOGAS DALAM DIGESTER SKALA MINI-PILOT
}

\author{
Johnner P. Sitompul ${ }^{1 *}$, Asep Bayu ${ }^{2}$, Tatang H. Soerawidjaja ${ }^{1}$, Hyung W. Lee ${ }^{1}$ \\ ${ }^{1}$ Program Studi Teknik Kimia, FTI, ITB, Jl. Ganesha 10, Bandung 40132 \\ ${ }^{2}$ Pusat Penelitian Oseanografi, LIPI, Jl. Pasir Putih I Ancol Timur, Jakarta 14430 \\ Email: sitompul@che.itb.ac.id
}

\begin{abstract}
Abstrak
Biomassa tanaman laut, khususnya makroalga, memiliki kadar lignin rendah sehingga biodegradabilitas anaerobiknya lebih tinggi dibandingkan tanaman darat. Dalam penelitian ini, biodegradabilitas anaerobik makroalga Ulva lactuca dan Padina sp. dari perairan Indonesia ditentukan berdasarkan produktivitas biogas, yang terutama diukur dari kadar metana yang dihasilkan. Peralatan berskala mini-pilot dirancang dan dirakit untuk mengukur perolehan biogas dari biomassa tanaman laut tersebut. Inokulum awal diperoleh dari campuran kotoran sapi dengan air. Biomassa basah dan air dicampur dan dihaluskan untuk memperoleh suspensi substrat. Inokulum dan suspensi substrat diumpankan ke dalam digester skala mini-pilot berkapasitas $5 \mathrm{~L}$ yang beroperasi secara semikontinu. Volume biogas diukur setiap hari sedangkan kadar metana diukur setiap 3 hari dengan kromatografi gas. Batang pisang digunakan sebagai biomassa pembanding. Produktivitas biogas yang dihasilkan dari Padina sp., U. lactuca, serta batang pisang berturut-turut yaitu 5,22, 4,88, dan 3,06 L, dengan kadar metana sebesar 64,85, 49,90, dan 34,76 \%-v/v. Kadar lignin pada biomassa berturut-turut sebesar 5,12, 1,54, dan 7,17 \%-b. Secara umum, makroalga memiliki kadar lignin relatif rendah sehingga biodegradabilitas anaerobiknya tinggi. Biodegradabilitas anaerobik paling tinggi dari Padina sp. juga disebabkan tingginya kadar senyawa yang dapat larut dalam air dan terhidrolisis. Nilai kalor kasar (HHV) biogas Padina sp. mendekati biogas kotoran sapi.
\end{abstract}

Kata kunci: makroalga, Ulva lactuca, Padina sp., biogas, HHV

\begin{abstract}
MARINE VEGETATION ANAEROBIC BIODEGRADATION AND BIOGAS PRODUCTION IN A MINI-PILOT DIGESTER. This paper describes the productivity of biogas from anaerobic biodegradation of macroalgae Ulva lactuca and Padina sp. Marine biomasses especially macroalgae contain less lignin, thus the anaerobic biodegradability of these biomasses was higher than terrestrial biomass. Banana stem waste was used as comparison for the feedstock. Initial inoculums were prepared from cow manure and water. The inoculums and substrates were fed into a mini-pilot digester, operating semi-continuously. Volume of biogas was measured daily while methane content was measured every 3 days using gas chromatograph. Biogas productivity from the mini-pilot digester for feedstock Padina sp., $U$. lactuca, and banana stem waste was 5.22, 4.88, and $3.06 \mathrm{~L}$ respectively, after 28 days operation, with methane content $64.85,49.90$, and $34.76 \%$-v/v, respectively. The study also shows that lignin content in Padina sp., U. lactuca, and banana stem waste were 5.12, 1.54, and $7.17 \%$-w respectively. In general, macroalgae have less lignin content and thus produce higher anaerobic biodegradability. The study shows that compounds in microalgae are more biodegradable and more hydrosoluble. Moreover, the experimental results also showed that gross heating value (HHV) of biogas from feedstock of Padina sp. was quite close to that of biogas from cow manure.
\end{abstract}

Keywords: Macroalgae, Ulva lactuca, Padina sp., biogas, HHV

*penulis korespondensi 


\section{PENDAHULUAN}

Wilayah pesisir dan pulau-pulau kecil di Indonesia memiliki kerentanan yang sangat tinggi terhadap energi. Hal ini disebabkan sulitnya akses ke daerah tersebut, rendahnya pengetahuan potensi sumber daya energi lokal dan masih minimnya kebijakan pengembangan energi pada wilayah tersebut (Ruchimat, 2011). Kebijakan yang ada lebih menitik beratkan pada pemanfaatan sumber daya yang ditujukan hanya untuk menyokong kebutuhan sektor listrik seperti angin, matahari, ombak, pasang surut dan bahkan energi termal samudera (OTEC) (Dewan Kelautan Indonesia, 2009). Namun demikian pengembangan energi berbasis sumbersumber daya tersebut masih terkendala baik pada ketersediaan serta intensitas energi yang yang bergantung pada lokasi, waktu, serta harga teknologi yang relatif mahal. Selain itu, kebutuhan energi untuk sektor bahan bakar rumah tangga juga menjadi kendala utama wilayah pesisir dan pulau-pulau kecil di Indonesia. Lebih jauh, efisiensi proses dan proses yang terintegrasi juga menjadi hal yang krusial dalam melakukan konservasi energi, khususnya dengan energi terbarukan yang menjadi fokus dalam penelitian di dunia (Sitompul dkk., 2012).

Biomassa tanaman laut khususnya makroalga dilaporkan memiliki biodegradabilitas anaerobik yang tinggi untuk produksi biogas. Hal ini disebabkan oleh kadar karbohidrat dan air yang relatif tinggi, serta kadar lignin yang relatif rendah (Burton dkk., 2009; Bruhn dkk., 2011; Chang dkk., 2010). Adapun jenis-jenis makroalga cokelat dan hijau merupakan kandidat potensial.

Indonesia memiliki keragaman makroalga yang tinggi. Namun demikian, potensi bioenergi kelautan berdasarkan biodegradabilitas anaerobik untuk produksi biogas masih belum banyak dilaporkan. Makroalga yang telah banyak dipelajari adalah yang memiliki nilai komersil seperti Eucheuma sp. (penghasil karageenan), Gracillaria sp. dan Gellidium sp. (penghasil agar-agar), juga Sargassum sp. (penghasil alginat) (Murdinah dkk., 2006). Indonesia masih memiliki jenis makroalga lain yang selain jumlahnya berlimpah, juga belum dimanfaatkan dengan baik seperti Ulva sp. dan Padina sp.

Penelitian ini bertujuan untuk mengetahui potensi biodegradabilitas anaerobik biomassa makroalga Ulva lactuca dan Padina sp. yang tumbuh di perairan Indonesia. Biodegradabilitas anaerobik ditentukan dari produktivitas biogas, yang dinyatakan oleh kadar metana dalam gas produk. Sebagai pembanding digunakan biomassa tanaman darat yaitu batang pisang yang memiliki karakteristik biomassa yang mirip dengan biomassa tanaman laut.

\section{METODE}

Peralatan skala mini-pilot digunakan pada studi perolehan biogas dari biomassa tanaman laut ini. Gambar 1 menunjukkan rangkaian peralatan mini-pilot dengan digester berkapasitas $5 \mathrm{~L}$.
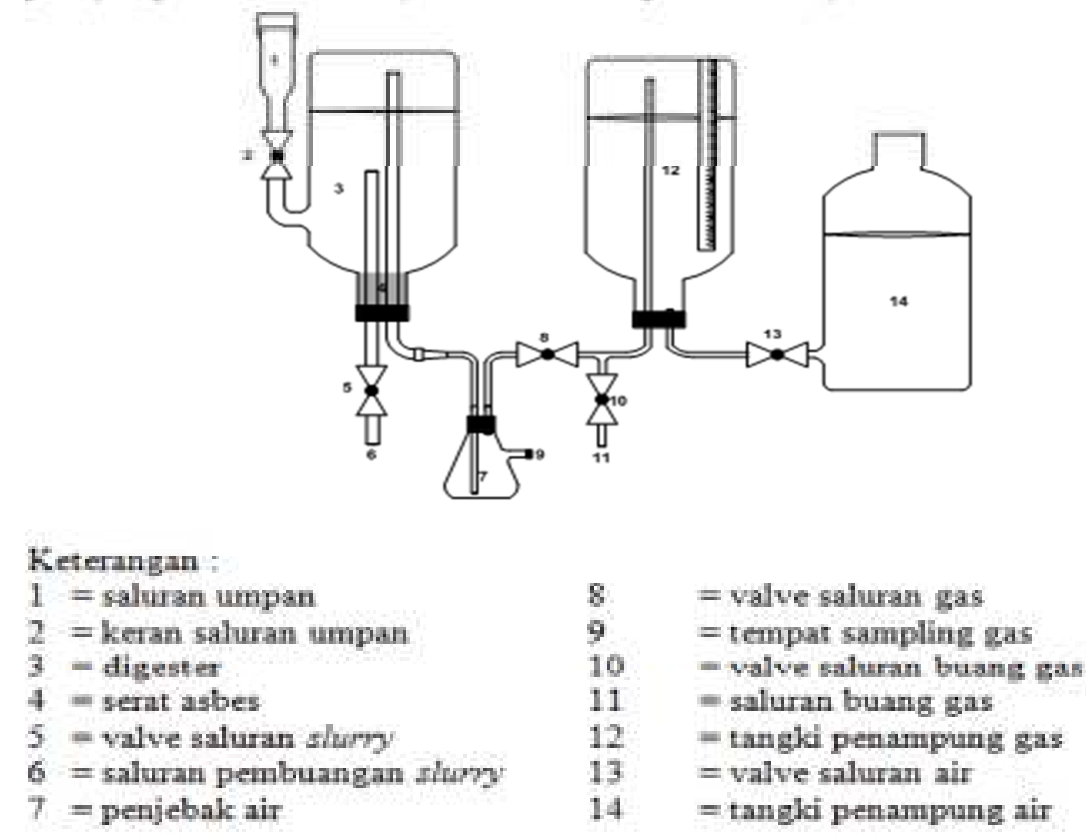

Gambar 1. Skema rangkaian digester skala mini-pilot berkapasitas $5 \mathrm{~L}$ 
Inokulum awal diperoleh dari campuran kotoran sapi dan air dengan perbandingan 1:1. Biomassa basah dan air dengan rasio 1:2 dicampur dan dihaluskan dengan blender untuk mem-peroleh suspensi substrat. Selanjutnya, 3,5 L campuran substrat dan inokulum dengan perbandingan 1:2 dimasukkan ke dalam digester mini-pilot. Umpan dimasukkan sebanyak $175 \mathrm{~mL}$ tiap 3 hari secara semikontinu. Volume biogas diukur setiap hari, sedangkan kadar metana diukur setiap 3 hari dengan kromatografi gas (GC) hingga hari ke-28. Batang pisang digunakan sebagai umpan biomassa pembanding. Makroalga sebagai umpan biomassa diperoleh dari wilayah pesisir Pantai Sayang Heulang, Pameungpeuk, Garut. Pengambilan biomassa dilakukan pada bulan Juli 2011 dengan menggunakan tangan. Biomassa basah selanjutnya dikeringkan dengan sinar matahari dan disimpan dalam karung plastik.

Tahap persiapan biomassa makroalga dilakukan dengan merendam biomassa kering dalam air selama 2 jam untuk mengembalikan bentuk awal biomassa. Selanjutnya, biomassa basah dicampur dengan air pada perbandingan 1:2 dan dihaluskan dengan blender. Perlakuan yang sama dilakukan pada preparasi substrat batang pisang. Persiapan inokulum awal dilakukan dengan mencampur kotoran sapi yang dicampur air pada perbandingan 1:1. Adapun pada proses selanjutnya, inokulum yang digunakan berasal dari proses biodegradasi anaerobik sebelumnya.

Penelitian proses biodegradasi anaerobik dilakukan dengan mencampur substrat dengan inokulum pada perbandingan 1:2. Sejumlah 3,5 L campuran tersebut dimasukkan ke dalam digester. Selanjutnya umpan segar substrat biomassa dimasukkan secara semi-kontinu ke dalam campuran dengan laju alir sebesar $175 \mathrm{~mL} / 3$ hari. Proses biodegradasi dilakukan pada temperatur kamar. Volume biogas yang dihasilkan diukur tiap hari (kecuali hari Sabtu dan Minggu) sedangkan kadar $\mathrm{CH}_{4}, \mathrm{CO}_{2}$, dan $\mathrm{H}_{2}$ diukur dengan menggunakan GC Shimadzu GC-8A dengan kolom Porapak Q, detektor TCD, dan kolom Molecular Sieve 5A. Parameter uji kebutuhan oksigen kimiawi (COD) dilakukan dengan metoda titrimetri menggunakan oksidator $\mathrm{K}_{2} \mathrm{Cr}_{2} \mathrm{O}_{7}$ yang diberikan secara lengkap dalam literatur (Bayu, 2012). Metode ini menggunakan larutan penitrasi Ferro amonium sulfat hingga warna larutan sampel menjadi merah bata. Pengukuran $\mathrm{pH}$ menggunakan indikator universal juga dilakukan pada slurry hasil proses biodegradasi anaerobik. Metoda penelitian dan metoda pengukuran yang sama dilakukan untuk biomassa batang pisang sebagai pembanding untuk perolehan biogas dari biomassa tersebut.

Karakterisasi biomassa dilakukan terhadap beberapa parameter uji seperti padatan total (TS), padatan menguap (VS), kadar abu, air (Bayu, 2012), lignin (Kim dkk., 2012), dan karbon organik total (TOC) (Bayu, 2012). Uji nyala bakar dilakukan terhadap biogas yang dari tiap proses dengan menggunakan pembakar bunsen. Adapun perhitungan nilai kalor kotor (HHV) dilakukan berdasarkan komposisi biogas yang dihasilkan merujuk pada Felder dan Rousseau (2005).

\section{HASIL DAN PEMBAHASAN}

Secara umum, makroalga menghasilkan produktivitas biogas yang lebih tinggi dibandingkan dengan batang pisang (Gambar 2). Hal tersebut menunjukkan bahwa makroalga memiliki komponen-komponen organik yang lebih mudah terbiodegradasi dibandingkan batang pisang. Makroalga cokelat Padina sp. lebih tinggi produktivitas biogasnya dibandingkan makroalga hijau $U$. lactuca. Makroalga cokelat umumnya dilaporkan memiliki biodegradabilitas yang lebih tinggi dibandingkan makroalga hijau (Burton dkk., 2009). Produktivitas biogas yang tinggi dari makroalga juga dapat disebabkan oleh kadar lignin yang rendah dibandingkan batang pisang (Tabel 1).

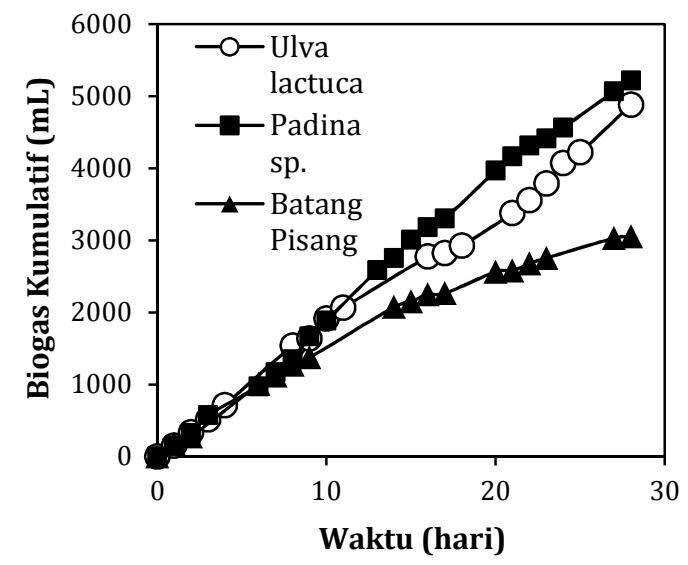

Gambar 2. Produktivitas biogas yang diperoleh dari tiap substrat biomassa 
Biodegradasi Anaerobik Biomassa Tanaman Laut (J. P. Sitompul, dkk.)

\begin{tabular}{llcrc}
\multicolumn{5}{c}{ Tabel 1. Karakteristik Substrat dari Tiap Biomassa } \\
\hline Parameter & Satuan & Ulva lactuca & Padina sp. & Batang Pisang \\
\hline TS $^{*}$ & $\%$-b/bb & 5,65 & 5,17 & 2,94 \\
VS & $\%-b k$ & 86,85 & 70,43 & 86,96 \\
Abu & $\%-b k$ & 13,15 & 29,57 & 13,04 \\
Air & $\%-b$ & 91,72 & 75,40 & 93,08 \\
Lignin & $\%-b k$ & 1,54 & 5,12 & 7,17 \\
TOC & $\%-b k$ & 28,29 & 35,71 & 41,38 \\
\hline
\end{tabular}

*setelah menjadi jus substrat, bk = berat kering, $\mathrm{bb}=$ berat basah

Lignin merupakan komponen organik yang paling sulit terbio-degradasi. Hal ini disebabkan karakteristik kimianya yang berupa senyawa polimer bermassa molekul tinggi dan berbasis fenil propana. Lignin juga menyelimuti komponen-komponen yang mudah terbiodegradasi seperti hemiselulosa dan selulosa sehingga mengurangi akses penetrasi enzim pengurai yang dihasilkan oleh bakteri pengurai. Namun demikian, hasil percobaan menunjukkan bahwa produktivitas biogas $U$. lactuca lebih kecil dibandingkan Padina sp. meskipun kadar ligninnya lebih rendah. Hal ini diduga disebabkan oleh adanya senyawa inhibitor lainnya yang menghambat proses biodegradasi. Senyawa inhibitor yang dapat mengganggu salah satunya adalah sulfur. Briand dan Morand (1997) melaporkan bahwa U. lactuca memiliki kadar sulfur cukup tinggi, berkisar antara 2,84,4 \%-b, yang dilaporkan menghambat aktivitas bakteri metanogenik (Burton dkk., 2009). Meskipun tidak dilakukan uji kadar sulfur, tingginya kadar sulfur pada $U$. lactuca ditandai dengan bau khas gas $\mathrm{H}_{2} \mathrm{~S}$ yang timbul terus menerus saat dilakukan proses pembakaran biogas.

Produktivitas metana pada biogas Padina sp. juga relatif tinggi dibandingkan biogas dari U. lactuca (Gambar 3). Hal tersebut menunjukkan laju metanogensis pada biogas Padina sp. tinggi yang disebabkan adanya komponen-komponen yang larut dalam air dan dapat terhidrolisis seperti alginat dan manitol. Briand dan Morand (1997) melaporkan bahwa manitol dan alginat lebih mudah terbiodegradasi dibandingkan hemiselulosa, selulosa dan lignin. Rendahnya laju metanogenesis disebabkan oleh adanya senyawa sulfur pada biomassa U. lactuca. Adanya sulfur dilaporkan menyebabkan terjadinya kompetisi antara reaksi metanogenesis yang menghasilkan metana dengan reduski sulfat yang menghasil

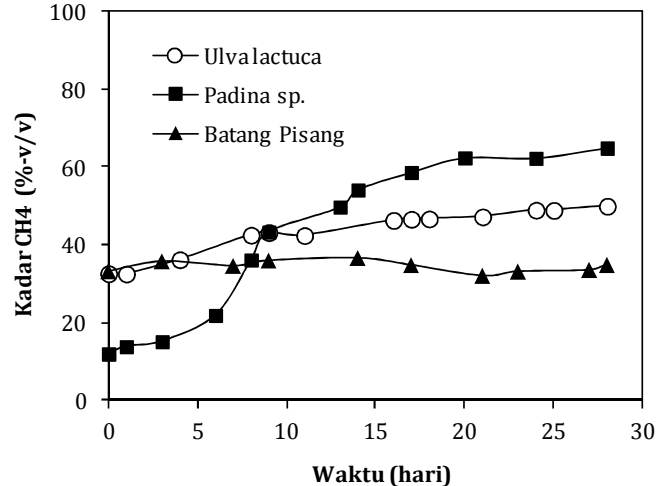

(a)

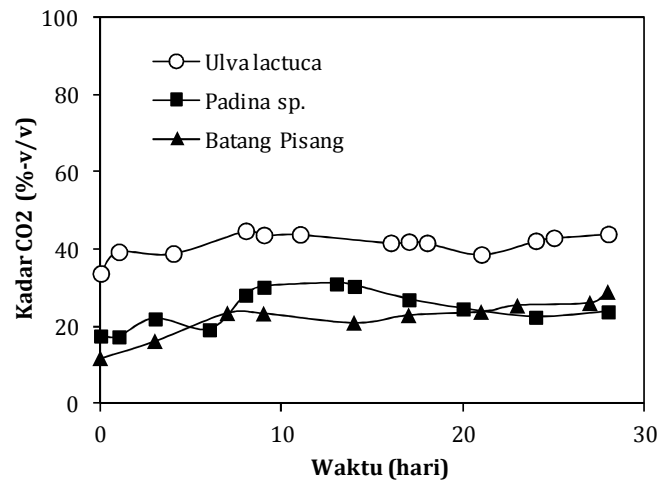

(b)

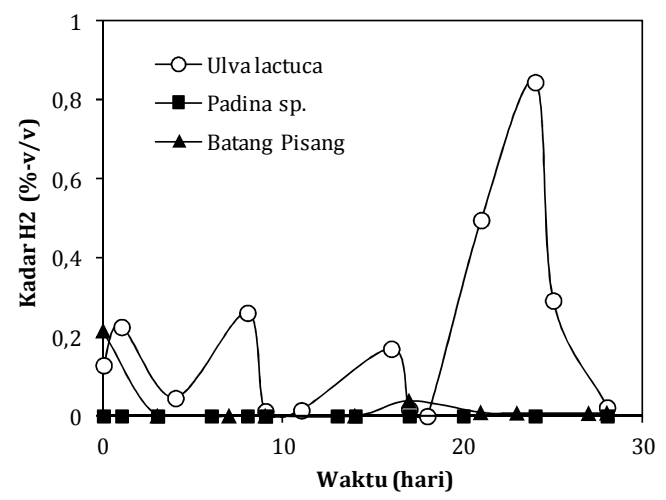

(c)

Gambar 3. Komposisi gas metana (a), karbon dioksida (b), dan hidrogen (c) yang terkandung pada biogas dari tiap substrat 
kan $\mathrm{H}_{2} \mathrm{~S}$. Dalam penelitian ini, meskipun tidak diukur, namun aroma khas gas $\mathrm{H}_{2} \mathrm{~S}$ tercium terus menerus pada saat dilakukan uji pembakaran dari biogas.

Tingginya proses biodegradasi anaerobik dari makroalga juga terlihat dari pengurangan nilai COD slurry dari tiap proses (Gambar 4). Hingga akhir proses pengurangan nilai COD Padina sp., U. lactuca dan batang pisang berturut-turut sebesar 72\%, 48,6\% dan 10,2\%. Dari gambar tersebut, hasil menunjukkan bahwa biodegradabilitas biomassa tanaman laut lebih cepat karena penurunan nilai COD dari biomassa Padina sp. dan U. lactuca menurun secara jauh lebih cepat dibandingkan biomassa daratan, seperti batang pisang.

Hasil pengujian nyala bakar menunjukkan bahwa biogas, yang dihasilkan dari digester skala mini-pilot, dapat terbakar dengan menghasilkan api berwarna biru dengan pembakaran menggunakan kompor Bunsen seperti ditunjukkan dalam Gambar 5 . Tinggi nyala berturut-turut, $7,5 \mathrm{~cm}, 6,3 \mathrm{~cm}$ dan $1,8 \mathrm{~cm}$ untuk biogas dari biomassa $U$. lactuca, Padina sp. dan Batang Pisang. Nyala api biogas dari batang pisang sangat kecil dan mudah padam karena kadar metana sangat rendah.

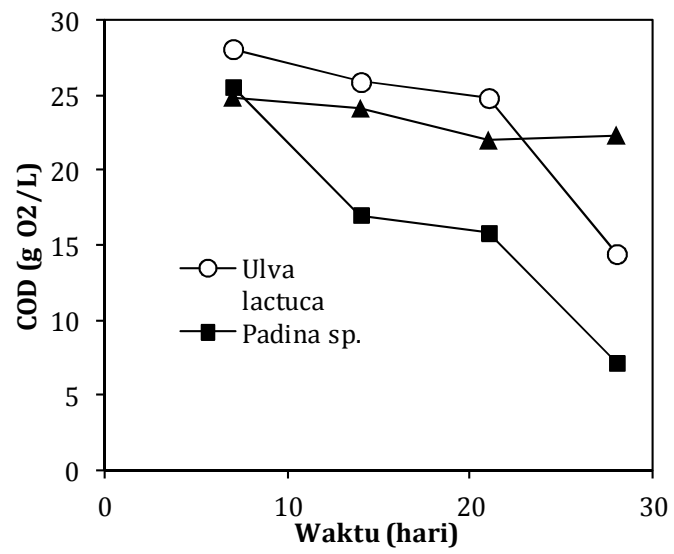

Gambar 4. Nilai kebutuhan oksidasi kimia (COD) dalam slurry terhadap waktu dari tiap biomassa selama proses biodegradasi anaerobik

Perhitungan nilai kalor HHV dari biogas dapat dilihat pada Tabel 2. Biogas dari biomassa Padina sp. mendekati nilai kalor HHV biogas dari kotoran sapi dan hasil ini sangat menjanjikan untuk penerapan produksi biogas dari bimassa tanaman laut yang sangat berlimpah di perairan Indonesia.

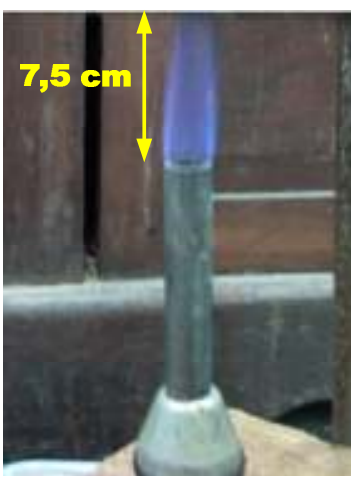

(a)

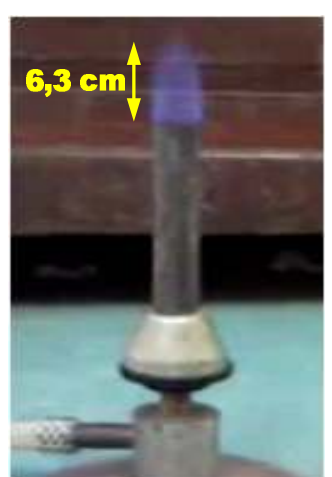

(b)

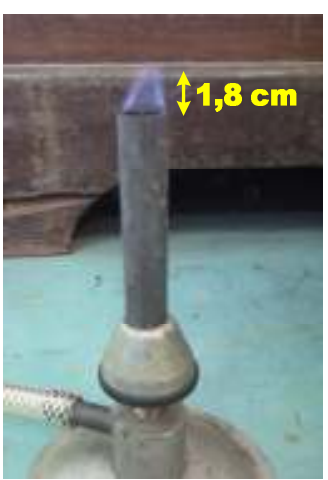

(c)

Gambar 5. Nyala bakar dari biogas yang dihasilkan tiap biomassa (a) U. lactuca, (b) Padina sp. dan (c) batang pisang

Tabel 2. Nilai Kalor HHV Biogas dari Tiap Substrat dan Bahan Bakar Umum

\begin{tabular}{|c|c|c|c|}
\hline \multirow{2}{*}{ Bahan Bakar } & \multicolumn{2}{|c|}{ Nilai Kalor HHV } & \multirow{2}{*}{ Sumber } \\
\hline & $\mathrm{kJ} / \mathrm{g}$ & $\mathrm{Btu} / \mathrm{lb}_{\mathrm{m}}$ & \\
\hline Kayu bakar & 17,0 & 7.700 & \multirow{3}{*}{$\begin{array}{l}\text { Felder dan Rousseau } \\
(2005)\end{array}$} \\
\hline Soft coal & 23,0 & 10.000 & \\
\hline Hard coal & 35,0 & 15.000 & \\
\hline Biogas dari kotoran sapi & 25,5 & 11.000 & \multirow[t]{2}{*}{ Perhitungan Teoritis * } \\
\hline Biogas dari U. lactuca & 15,3 & 6.563 & \\
\hline Biogas dari Padina sp. & 24,0 & 10.300 & \multirow[t]{2}{*}{ Hasil Penelitian ini } \\
\hline Biogas dari Batang Pisang & 10,8 & 4.643 & \\
\hline
\end{tabular}




\section{KESIMPULAN}

Makroalga asal perairan Indonesia memiliki potensi untuk dijadikan substrat dalam proses biodegradasi anaerobik untuk penghasil biogas dalam skala mini-pilot. Makroalga cokelat Padina sp. menghasilkan produktivitas biogas dan metana yang tinggi dibandingkan makroalga hijau U. lactuca. Secara umum, makroalga memiliki kadar lignin relatif rendah sehingga biodegradabilitas anaerobiknya tinggi. Biodegradabilitas anaerobik paling tinggi dari Padina sp. juga disebabkan tingginya kadar senyawa hydrolysable dan hydrosoluble seperti alginat dan manitol yang mudah terbiodegradasi dibandingkan hemiselulosa, selulosa dan lignin. Selain ketersediaan biomassa yang melimpah, biogas yang dihasilkan memberikan nyala api biru. Produksi biogas dari biomassa tanaman laut dalam digester skala mini-pilot lebih tinggi dari biomassa tanaman darat batang pisang, dengan produksi biogas 5,22 L, 4,88 L, 3,06 L (diukur pada kondisi standar) selama 28 hari untuk tiap biomassa Padina Sp., Ulva lactuca dan pohon pisang dengan kandungan metana dalam biogas berturut-turut $64,85,49,90$, dan $34,76 \%$-v/v. Nilai kalor kasar (HHV) biogas yang dihasilkan dari biomassa Padina sp. sebesar 24,0 kJ/g, mendekati nilai HHV biogas dari kotoran sapi, yakni 25,5 kJ/g. Hasil penelitian produksi biogas dari makroalga dalam digester skala mini-pilot ini sangat menggembirakan dan menunjukkan peluang pengembangan pada wilayah pesisir dan pulau-pulau kecil di Indonesia sebagai sumber energi untuk kesejahteraan masyarakat pesisir.

\section{UCAPAN TERIMA KASIH}

Penulis kedua (AB) mengucapkan terima kasih atas beasiswa Magister dari Kementrian Riset dan Teknologi Republik Indonesia. Penulis keempat (HWL) mengucapkan terima kasih kepada National Research Foundation Korea, atas pendanaan untuk visiting scholar periode 2012-2013, di Program Studi Teknik Kimia, Fakultas Teknologi Industri, Institut Teknologi Bandung. Para penulis juga mengucapkan terima kasih kepada Bapak Komari selama penelitian, khususnya analisis biogas dengan GC.

\section{DAFTAR PUSTAKA}

Bayu, A. Biodegradasi Anaerobik Biomassa Tanaman Laut, Tesis Magister, Institut Teknologi Bandung, Juli 2012.

Briand, X.; Morand, P., Anaerobic digestion of Ulva sp. 1. relationship between Ulva sp. composition and methanisation, Journal of Applied Phycology, 1997, 9(6), 511-524.

Bruhn, A.; Dahl, J.; Nielsen, H. B.; Nikolaisen, L.; Rasmussen, M. B.; Markager, S.; Olesen, B.; Arias, C.; Jensen, P. D., Bioenergy potential of Ulva lactuca: biomass yield, methane production and combustion, Bioresource Technology, 2011, 102(3), 2595-2604.

Burton, T.; Lyons, H.; Lerat, Y.; Stanley, M.; Rasmussen, M. B., A Review of the Potential of Marine Algae as A Source of Biofuel in Ireland; Sustainable Energy Ireland Report Ireland, February 2009.

Chang, H. N.; Kim, N. J.; Kang, J.; Jeong, C. M., Biomass-derived volatile fatty acid platform for fuels and chemicals, Biotechnology and Bioprocess Engineering, 2010, 15(1), 1-10.

Dewan Kelautan Indonesia, Perumusan Kebijakan Energi dan Sumber Daya Mineral Kelautan 2009; Departemen Kelautan dan Perikanan: Indonesia, 2009; hlm. 6-72.

Felder, R. M.; Rousseau, R. W., Elementary Principles of Chemical Processes; 3rd Ed., John Wiley and Sons: United States of America, 2005; hlm. 448-475.

Kim, S. J.; Kim, M. Y.; Jeong, S. J.; Jang M. S.; Chung, III M., Analysis of the biomass content of various Miscanthus genotypes for biofuel production in Korea, Industrial Crops and Products, 2012, 38, 46-49.

Murdinah; Irianto, H. E.; Peranginangin, R.; Subaryono; Sinurat, E.; Darmawan, M.; Fransiska, D., Riset Teknik Pembuatan Biogas Sebagai Sumber Energi; Laporan Riset Balai Besar Riset Pengolahan Produk dan Bioteknologi Kelautan dan Perikanan: Indonesia, 2006.

Ruchimat, T., Kebijakan Pengembangan Kawasan Pesisir dan Pulau-Pulau Kecil Berbasis Energi Bersih, Direktorat Jenderal Kelautan, Pesisir dan Pulau-Pulau Kecil- 
Kementrian Kelautan dan Perikanan: Indonesia, 2011, hlm. 1-38.

Sitompul, J. P.; Widayat.; Soerawidjaja, T. H., Evaluation and modification of processes for bioethanol separation and production, International Journal of Renewable Energy Development (IJRED), 2012, 1(1), 15-22.
Soerawidjaja, T. H., Biogas, Bahan kuliah Teknologi Kemurgi TK 5038 Modul 13, Institut Teknologi Bandung, Bandung: 2009, hlm. 1-30. 